in vivo $34: 1909-1913(2020)$

doi:10.21873/invivo.11987

\title{
Survival After Stereotactic Radiosurgery (SRS) or Fractionated Stereotactic Radiotherapy (FSRT) for Cerebral Metastases in the Elderly
}

\author{
DIRK RADES ${ }^{1}$, TRANG NGUYEN ${ }^{1}$, OLIVER BLANCK $^{2}$ and STEVEN E. SCHILD ${ }^{3}$ \\ ${ }^{1}$ Department of Radiation Oncology, University of Lübeck, Lübeck, Germany; \\ ${ }^{2}$ Saphir Radiosurgery Center Northern Germany, Güstrow, Germany; \\ ${ }^{3}$ Department of Radiation Oncology, Mayo Clinic, Scottsdale, AZ, U.S.A.
}

\begin{abstract}
Background/Aim: Stereotactic radiosurgery (SRS) and fractionated stereotactic radiotherapy (FSRT) have gained popularity especially for treating $1-3$ cerebral metastases. Elderly patients benefit from treatment personalisation. A specific survival score was created to facilitate this approach. Patients and Methods: Ten characteristics were retrospectively analysed for survival in 104 elderly patients with 1-3 cerebral metastases receiving SRS or FSRT alone using a linear accelerator or

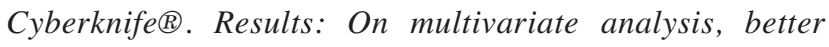
survival was significantly associated with KPS of 90-100 $(p=0.049)$, single lesion $(p=0.036)$, maximum cumulative diameter of all lesions $<16 \mathrm{~mm}(p=0.026)$ and supratentorial involvement only ( $p=0.047)$. Three groups were formed with 12-14 points $(n=22), 15-16$ points $(n=33)$ and $17-19$ points $(n=49)$ with 12-month survival rates of $7 \%, 34 \%$ and $58 \%$ $(p<0.0001)$, respectively. Positive predictive values for predicting death $\leq 12$ months and survival $\geq 12$ months were 95\% and 54\%. Conclusion: The new score showed very high accuracy in predicting death $\leq 12$ months, but not in predicting survival $\geq 12$ months.
\end{abstract}

For about 10 years after a randomized trial suggested less cognitive decline after radiosurgery alone than after radiosurgery plus whole-brain irradiation, stereotactic radiosurgery (SRS) and fractionated stereotactic radiotherapy

This article is freely accessible online.

Correspondence to: Professor Dirk Rades, MD, Department of Radiation Oncology, University of Lubeck, Lubeck, Ratzeburger Allee 160, 23562 Lubeck, Germany. Tel: +49 45150045401, Fax: +49 45150045404, e-mail: rades.dirk@gmx.net

Key Words: Cerebral metastases, stereotactic radiosurgery, fractionated stereotactic radiotherapy, elderly, treatment personalisation.
(FSRT) alone have become increasingly popular for patients with a low number of cerebral metastases $(1,2)$. Since it can be difficult for older patients to tolerate aggressive local treatments, the pros and cons of such treatment regimens must be carefully considered. Important aspects that have to be taken into account include a patient's estimated lifespan and potential reasons for death including intra-cerebral disease progression and extra-cerebral metastatic spread (3$5)$. Depending on the remaining lifespan and the probable reason for death, the treatment protocols may differ. For patients with a good survival prognosis, the risk of late treatment-related morbidity and long-term disease control are very important (4). If the prognosis is quite limited, the treatment regimen should be minimally burdensome and time-consuming, as well as medically reasonable. Therefore, physicians need to be able to estimate a patient's prognosis before designing their treatment regimen. Several survival scores have already been introduced, including a score for elderly patients with cerebral metastases treated with Gamma Knife radiosurgery and a score for patients of any age treated with radiosurgery from a conventional linear accelerator or a Cyberknife ${ }^{\circledR}$, i.e. with photon beams (5-7). However, no specific scoring system is currently available for older patients receiving radiosurgery with photon beams. This study was performed to provide such an additional instrument.

\section{Patients and Methods}

Ten characteristics were analysed for survival in a series of 104 patients with one to three cerebral metastases, who were $\geq 65$ years of age and had received SRS or FSRT alone (Table I). This retrospective study received approval by the local Ethics Committee (number 19-011A). SRS and FSRT were performed with photon beams from a conventional linear accelerator $(n=73)$ or a Cyberknife $^{\circledR}(\mathrm{n}=31)$. The 10 characteristics were the equivalent dose in 2 Gy fractions (EQD2) of SRS and FSRT (18-19 Gy versus 20 Gy and $21-25 \mathrm{~Gy}$ ), age ( $\leq 70$ versus $\geq 71$ years), gender, Karnofsky 
performance score (70-80 versus 90-100), type of primary tumour (cancer of the breast versus cancer of the lung, kidney cancer, melanoma, colorectal cancer and other types), number of lesions (1 versus 2 or 3$)$, maximum cumulative diameter of all lesions $(<16$ versus $\geq 16 \mathrm{~mm}$ ), sites of the lesions (supratentorial only versus infratentorial \pm supratentorial), extra-cerebral spread (yes versus no), and interval between tumour diagnosis and irradiation ( $\leq 18$ versus $\geq 19$ months).

Survival analyses were conducted with the Kaplan-Meier method plus the log-rank test. Characteristics showing a significant correlation, defined as $p<0.05$, with survival on these univariate analyses, were subsequently evaluated for independence using a Cox regression model. If significance was achieved in the Cox regression analysis, the characteristic did qualify for inclusion in the survival score. The survival rates at 12 months, referenced from the day of SRS or the first day of FSRT, were divided by 10 . The scoring points obtained from this procedure were summed to obtain the individual scores for each of the 104 patients.

\section{Results}

For four characteristics, significant associations with survival were observed in the univariate analysis (Table II). These were the KPS $(p=0.013)$, the number of lesions $(p=0,002)$, maximum cumulative diameter of all lesions $(p=0.003)$ and sites of the lesions $(p=0.021)$. Better survival was associated with KPS of 90-100, only a single lesion, a maximum cumulative diameter of $<16 \mathrm{~mm}$ and supratentorial involvement only. When evaluated in a multivariate Cox regression method, all four characteristics were found to be independent predictors of survival and used for building the new score (Table III). The corresponding scoring points are shown in Table IV.

The resulting total scores for individual patients ranged from 12 to 19 points (Table V). When considering the 12month survival rates related to these scores, three groups were formed, namely with $12-14$ points $(n=22), 15-16$ points $(n=33)$ and $17-19$ points $(n=49)$. The 12-month survival rates of these groups were $7 \%, 34 \%$ and $58 \%$, respectively, and the median survival times were 4,8 and 19 months, respectively ( $p<0.0001$, Figure 1$)$. In the group with 12-14 points, the reasons for death were intra-cerebral progression in seven patients, extra-cerebral progression in six, both intra- and extra-cerebral progression in five and other reasons in two. The corresponding numbers were 10, 14, three and one patient, respectively, in the group with 15-16 points, and 12, nine, zero and two, respectively, in the group with 17-19 points.

Fifteen patients were alive at their last follow-up visit but their maximum follow-up time was less than 12 months. Positive predictive values (PPVs) for correct prediction of death within 12 months and survival for at least 12 months were calculated by dividing the number of true positives by the total number of patients. These calculations were performed for the remaining 89 patients. The PPV for
Table I. Characteristics of the 104 patients included in this study.

\begin{tabular}{|c|c|}
\hline Characteristic & Number of patients \\
\hline \multicolumn{2}{|l|}{ Radiation dose (EQD2) } \\
\hline 18-19 Gy & $23(22 \%)$ \\
\hline 20 Gy & $61(59 \%)$ \\
\hline $21-25$ Gy & $20(19 \%)$ \\
\hline \multicolumn{2}{|l|}{ Age } \\
\hline$\leq 70$ Years & $56(54 \%)$ \\
\hline$\geq 71$ Years & $48(46 \%)$ \\
\hline \multicolumn{2}{|l|}{ Gender } \\
\hline Female & $45(43 \%)$ \\
\hline Male & $59(57 \%)$ \\
\hline \multicolumn{2}{|l|}{ KPS } \\
\hline $70-80$ & $50(48 \%)$ \\
\hline $90-100$ & $54(52 \%)$ \\
\hline \multicolumn{2}{|l|}{ Type of primary tumour } \\
\hline Breast cancer & $6(6 \%)$ \\
\hline Lung cancer & $26(25 \%)$ \\
\hline Kidney cancer & $15(14 \%)$ \\
\hline Melanoma & $43(41 \%)$ \\
\hline Colorectal cancer & $7(7 \%)$ \\
\hline Other types & $7(7 \%)$ \\
\hline \multicolumn{2}{|l|}{ Number of lesions } \\
\hline 1 & $66(63 \%)$ \\
\hline 2 or 3 & $38(37 \%)$ \\
\hline \multicolumn{2}{|l|}{ Maximum diameter of lesions } \\
\hline$<16 \mathrm{~mm}$ & $52(50 \%)$ \\
\hline$\geq 16 \mathrm{~mm}$ & $52(50 \%)$ \\
\hline \multicolumn{2}{|l|}{ Sites of lesions } \\
\hline Supratentorial only & $74(71 \%)$ \\
\hline Infratentorial \pm supratentorial & $30(29 \%)$ \\
\hline \multicolumn{2}{|l|}{ Extra-cerebral spread } \\
\hline Yes & $67(64 \%)$ \\
\hline No & $37(36 \%)$ \\
\hline \multicolumn{2}{|l|}{$\begin{array}{l}\text { Interval between tumour } \\
\text { diagnosis and irradiation }\end{array}$} \\
\hline$\leq 18$ Months & $50(48 \%)$ \\
\hline$\geq 19$ Months & $54(52 \%)$ \\
\hline
\end{tabular}

EQD2: Equivalent dose in 2 Gy fractions; KPS: Karnofsky performance score

predicting death correctly in the $12-14$ point group within 12 months was 95\%; and the PPV for predicting survival in the 17-19 point group for 12 months or longer was $54 \%$.

\section{Discussion}

For older patients with a very limited number of cerebral metastases, different types of treatment are available including neurosurgical resection, SRS, FSRT and wholebrain irradiation, as well as combinations of these treatments (8). In a previous study of 164 patients aged $\geq 65$ years, best results in terms of survival, intra-cerebral control and local control of the treated lesions were achieved with resection followed by whole-brain irradiation and a radiation boost to 
Table II. Survival rates at 6 and at 12 months following radiosurgery or fractionated stereotactic radiotherapy.

\begin{tabular}{|c|c|c|c|}
\hline \multirow[b]{2}{*}{ Characteristic } & \multicolumn{2}{|c|}{ Survival rate } & \multirow[b]{2}{*}{$p$-Value } \\
\hline & $\begin{array}{l}6 \text { Months } \\
(\%)\end{array}$ & $\begin{array}{l}12 \text { Months } \\
(\%)\end{array}$ & \\
\hline \multicolumn{4}{|l|}{ Radiation dose (EQD2) } \\
\hline 18-19 Gy & 61 & 36 & 0.50 \\
\hline $20 \mathrm{~Gy}$ & 59 & 40 & \\
\hline $21-25 \mathrm{~Gy}$ & 75 & 46 & \\
\hline \multicolumn{4}{|l|}{ Age } \\
\hline$\leq 70$ Years & 64 & 43 & 0.13 \\
\hline$\geq 71$ Years & 60 & 37 & \\
\hline \multicolumn{4}{|l|}{ Gender } \\
\hline Female & 58 & 31 & 0.75 \\
\hline Male & 66 & 47 & \\
\hline \multicolumn{4}{|l|}{ KPS } \\
\hline $70-80$ & 48 & 32 & 0.013 \\
\hline $90-100$ & 76 & 48 & \\
\hline \multicolumn{4}{|l|}{ Type of primary tumour } \\
\hline Breast cancer & 83 & 83 & 0.31 \\
\hline Lung cancer & 69 & 40 & \\
\hline Kidney cancer & 47 & 31 & \\
\hline Melanoma & 67 & 38 & \\
\hline Colorectal cancer & 43 & 43 & \\
\hline Other types & 43 & 21 & \\
\hline \multicolumn{4}{|l|}{ Number of lesions } \\
\hline 1 & 71 & 48 & 0.002 \\
\hline 2 or 3 & 47 & 27 & \\
\hline \multicolumn{4}{|l|}{ Maximum diameter of lesions } \\
\hline$<16 \mathrm{~mm}$ & 73 & 52 & 0.003 \\
\hline$\geq 16 \mathrm{~mm}$ & 52 & 27 & \\
\hline \multicolumn{4}{|l|}{ Sites of lesions } \\
\hline Supratentorial only & 69 & 43 & 0.021 \\
\hline Infratentorial \pm supratentorial & 47 & 33 & \\
\hline \multicolumn{4}{|l|}{ Extra-cerebral spread } \\
\hline Yes & 51 & 36 & 0.18 \\
\hline No & 84 & 46 & \\
\hline \multicolumn{4}{|l|}{$\begin{array}{l}\text { Interval between tumour } \\
\text { diagnosis and irradiation }\end{array}$} \\
\hline$\leq 18$ Months & 66 & 36 & 0.52 \\
\hline$\geq 19$ Months & 59 & 44 & \\
\hline
\end{tabular}

EQD2: Equivalent dose in 2 Gy fractions; KPS: Karnofsky performance score. Significant $p$-values are shown in bold.

Table III. Results of the Cox regression analysis for independence.

\begin{tabular}{lccc}
\hline Characteristic & $\begin{array}{r}\text { Risk } \\
\text { ratio }\end{array}$ & $\begin{array}{c}95 \% \text { Confidence } \\
\text { interval }\end{array}$ & $p$-Value \\
\hline KPS & 1.62 & $1.00-2.65$ & $\mathbf{0 . 0 4 9}$ \\
Number of lesions & 1.70 & $1.04-2.78$ & $\mathbf{0 . 0 3 6}$ \\
Maximum diameter of lesions & 1.75 & $1.07-2.90$ & $\mathbf{0 . 0 2 6}$ \\
Sites of lesions & 1.74 & $1.01-2.94$ & $\mathbf{0 . 0 4 7}$ \\
\hline
\end{tabular}

KPS: Karnofsky performance score. Significant $p$-values are shown in bold.

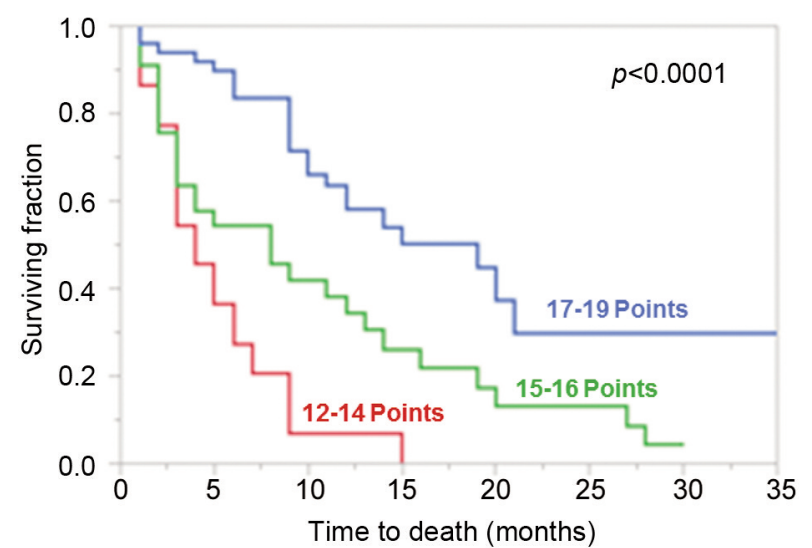

Figure 1. Kaplan-Meier curves of patients with 12-14 points $(n=22)$, $15-16$ points $(n=33)$ and $17-19$ points $(n=49)$.

Table IV. Independent characteristics and their scoring points.

\begin{tabular}{lcc}
\hline Characteristic & $\begin{array}{c}\text { 12-Month } \\
\text { survival (\%) }\end{array}$ & $\begin{array}{c}\text { Scoring } \\
\text { points }\end{array}$ \\
\hline KPS & & \\
$\quad 70-80$ & 32 & 3 \\
$90-100$ & 48 & 5 \\
Number of lesions & 48 & 5 \\
$\quad \begin{array}{l}1 \\
2 \text { or } 3\end{array}$ & 27 & 3 \\
Maximum diameter of lesions & 52 & 5 \\
$\quad<16$ mm & 27 & 3 \\
$\quad \geq 16$ mm & & \\
Sites of lesions & 43 & 4 \\
$\quad$ Supratentorial only & 33 & 3 \\
Infratentorial \pm supratentorial & & \\
\hline
\end{tabular}

KPS: Karnofsky performance score.

Table V. Scoring points and related 6- and 12-month survival rates.

\begin{tabular}{|c|c|c|c|}
\hline \multirow[b]{2}{*}{ Scoring points } & \multicolumn{2}{|c|}{ Survival rate } & \multirow[b]{2}{*}{$p$-Value } \\
\hline & $\begin{array}{l}6 \text { Months } \\
(\%)\end{array}$ & $\begin{array}{c}12 \text { Months } \\
(\%)\end{array}$ & \\
\hline 12 & 17 & 17 & $<0.0001$ \\
\hline 13 & 40 & 0 & \\
\hline 14 & 17 & $\mathrm{n} \cdot \mathrm{a}$ & \\
\hline 15 & 57 & 38 & \\
\hline 16 & 50 & 27 & \\
\hline 17 & 85 & 56 & \\
\hline 18 & 100 & 83 & \\
\hline 19 & 76 & 54 & \\
\hline
\end{tabular}

n.a.: Not available. Significant $p$-values are shown in bold. 
the resection cave (8). The corresponding rates at 1 year were $61 \%, 79 \%$ and $84 \%$, respectively. However, many older patients cannot withstand an aggressive treatment like brain surgery. In the previous study, the second most favourable results were obtained after SRS alone with 1-year rates of $40 \%$ (survival), 55\% (intra-cerebral control) and 68\% (local control), respectively (8). Thus, SRS alone appears to be a good option for older patients with very few lesions who cannot receive or reject neurosurgical resection. Singlefraction SRS has the advantage that it takes only one day, since it is administered in a single treatment session, whereas FSRT is usually given in three to seven daily fractions (9). However, since the dose per fraction of FSRT is lower compared to SRS, it may be associated with less late damage to the surrounding normal brain tissue and critical organs (e.g. brain stem, optic chiasm, optic nerves, and cochlea), if they are close to the metastases. In a study of 298 patients that compared single-fraction SRS to FSRT for cerebral metastases $>2 \mathrm{~cm}$, the rates of radio-necrosis after 1 year were $18 \%$ and $9 \%$, respectively $(p=0.01)(10)$. Although SRS and FSRT are high-precision techniques, structures close to the target volumes may receive considerable doses. Therefore, FSRT should be considered for patients with favourable survival prognoses. Moreover, in a previous study, FSRT resulted in significantly better 1-year control of irradiated lesions than did SRS (91\% versus 77\%, $p=0.01$ ) (10).

In order to improve the survival of patients with cerebral metastases, SRS and FSRT are increasingly more commonly combined with novel targeted therapies (11). Sequential treatment with radiotherapy using high doses per fraction and a targeted therapy may result in significant necrosis of brain tissue that can affect a volume considerable larger than the volume of the cerebral lesions $(12,13)$. On the contrary, older patients with less favourable survival should receive short-course treatments to optimally enjoy their limited lifetime. Thus, single-fraction SRS may be preferable for these patients.

In order to be able to judge an older patient's survival prognosis prior to treatment of one to three cerebral metastases, we have generated a specific survival score for this group. Patients of the group with 12-14 points had a poor prognosis with a median survival time of only 4 months. These patients should be considered for single-fraction SRS, preferably with volume-modulated arc therapy, since this treatment takes considerably less time than classic radiosurgery (14). If volume-modulated arc therapy is not available, whole-brain irradiation can be a reasonable alternative. Patients of the group with 15-16 points had an intermediate prognosis, with a median survival time of 8 months. Since the risk of experiencing cognitive deficits increases with lifetime, such patients may be considered for FSRT instead of SRS. Patients of the group with 17-19 points had the most favourable prognosis, with a median survival time of 19 months and, therefore, appear to be good candidates for FSRT. When following these recommendations, one should keep in mind that this new score was created from retrospective data, which may have introduced a hidden bias.

Since in the three groups of the new score, 39-61\% of deaths occurred due to extra-cerebral progression, systemic treatment may be considered for all patients. However, the side-effects of these agents need to be considered, and riskbenefit analyses must be thoroughly performed, particularly because the tolerance of older patients regarding systemic treatments is generally lower than that of younger persons.

Moreover, intra-cerebral progression was the cause of death in $46-65 \%$ of patients; whole-brain irradiation in addition to SRS or FSRT appears reasonable for a considerable number of patients of all three groups. This approach has been shown to increase the rate of freedom from intra-cerebral progression significantly when compared to SRS alone (15). When considering the addition of wholebrain irradiation, modern approaches, namely hippocampalsparing radiotherapy and memantine, can significantly reduce cognitive decline (16). Moreover, with another scoring system, the risk of developing new distant brain metastases can be assessed. However, this scoring system was created in patients of any age and may be applicable to the group of older patients only with reservations (3).

In summary, a new survival score was developed particularly for older patients with one to three cerebral metastases assigned to SRS or FSRT alone. This score showed very high accuracy in predicting death within 12 months but not in predicting survival for 12 months or longer.

\section{Conflicts of Interest}

On behalf of all Authors, the corresponding Author states that there are no conflicts of interest related to this study.

\section{Authors' Contributions}

D.R., T.N. and S.E.S, designed the study. T.N., O.B. and D.R. collected or provided data that were analysed by D.R. and S.E.S. The draft of the article written by D.R. and S.E.S. was reviewed and approved by all Authors.

\section{References}

1 Chang EL, Wefel JS, Hess KR, Allen PK, Lang FF, Kornguth DG, Arbuckle RB, Swint JM, Shiu AS, Maor MH and Meyers CA: Neurocognition in patients with brain metastases treated with radiosurgery or radiosurgery plus whole-brain irradiation: A randomised controlled trial. Lancet Oncol 10: 1037-1044, 2009. PMID: 19801201. DOI: 10.1016/S1470-2045(09)70263-3

2 Dziggel L, Bajrovic A, Schild SE and Rades D: Stereotactic radiosurgery alone for one to two brain metastases from cancer of unknown primary. Anticancer Res 38: 565-567, 2018. PMID: 29277825. DOI: 10.21873 /anticanres. 12260 
3 Huttenlocher S, Dziggel L, Hornung D, Blanck O, Schild SE and Rades D: A new prognostic instrument to predict the probability of developing new cerebral metastases after radiosurgery alone. Radiat Oncol 9: 215, 2014. PMID: 25240823. DOI: 10.1186/ 1748-717X-9-215

4 Evers JN, Schild SE, Segedin B, Nagy V, Khoa MT, Trang NT and Rades D: A new score predicting survival prognosis after whole-brain radiotherapy alone for brain metastases in elderly patients. Anticancer Res 34: 2455-2458, 2014. PMID: 24778060.

5 Rades D, Huttenlocher S, Dziggel L, Blanck O, Hornung D, Mai KT, Ngo TT, Van Pham T and Schild S: A new tool to predict survival after radiosurgery alone for newly diagnosed cerebral metastases. Asian Pac J Cancer Prev 16: 2967-2970, 2015. PMID: 25854390. DOI: 10.7314/apjcp.2015.16.7.2967

6 Rades D, Blanck O, Khoa MT, VAN Thai P, Hung NQ, Dziggel L and Schild SE: Validation of a survival score for patients receiving radiosurgery or fractionated stereotactic radiotherapy for 1 to 3 brain metastases. In Vivo 32: 381-384, 2018. PMID: 29475924. DOI: 10.21873/invivo.11249

7 Yamamoto M, Serizawa T, Higuchi Y, Nagano O, Aiyama H, Koiso T, Watanabe S, Kawabe T, Sato Y and Kasuya H: Prognostic grading system specifically for elderly patients with brain metastases after stereotactic radiosurgery: A 2-institution study. J Neurosurg 129(Suppl 1): 95-102, 2018. PMID: 30544299. DOI: $10.3171 / 2018.7 . G K S 181458$

8 Rades D, Pluemer A, Veninga T and Schild SE: Comparison of different treatment approaches for one to two brain metastases in elderly patients. Strahlenther Onkol 184: 565-571, 2008. PMID: 19016014. DOI: 10.1007/s00066-008-1908-1

9 Tsao MN, Rades D, Wirth A, Lo SS, Danielson BL, Gaspar LE, Sperduto PW, Vogelbaum MA, Radawski JD, Wang JZ, Gillin MT, Mohideen N, Hahn CA and Chang EL: Radiotherapeutic and surgical management for newly diagnosed brain metastasis(es): An American Society for Radiation Oncology evidence-based guideline. Pract Radiat Oncol 2: 210-225, 2012. PMID: 25925626. DOI: 10.1016/j.prro.2011.12.004

10 Minniti G, Scaringi C, Paolini S, Lanzetta G, Romano A, Cicone F, Osti M, Enrici RM and Esposito V: Single-fraction versus multifraction $(3 \times 9$ Gy) stereotactic radiosurgery for large $(>2$ $\mathrm{cm})$ brain metastases: A comparative analysis of local control and risk of radiation-induced brain necrosis. Int J Radiat Oncol Biol Phys 95: 1142-1148, 2016. PMID: 27209508. DOI: 10.1016/j.ijrobp.2016.03.013
11 Stera S, Balermpas P, Blanck O, Wolff R, Wurster S, Baumann R, Szücs M, Loutfi-Krauss B, Wilhelm ML, Seifert V, Rades D, Rödel C, Dunst J, Hildebrandt G, Arnold A, Meissner M and Kähler KC: Stereotactic radiosurgery combined with immune checkpoint inhibitors or kinase inhibitors for patients with multiple brain metastases of malignant melanoma. Melanoma Res 29: 187-195, 2019. PMID: 30802230 . DOI: 10.1097/CMR.0000000000000542

$12 \mathrm{Du}$ Four S, Hong A, Chan M, Charakidis M, Duerinck J, Wilgenhof S, Wang W, Feng L, Michotte A, Okera M, Shivalingam B, Fogarty G, Kefford R and Neyns B: Symptomatic histologically proven necrosis of brain following stereotactic radiation and ipilimumab in six lesions in four melanoma patients. Case Rep Oncol Med 2014: 417913, 2014.

13 Du Four S, Janssen Y, Michotte A, Van Binst AM, Van den Begin R, Duerinck J and Neyns: Focal radiation necrosis of the brain in patients with melanoma brain metastases treated with pembrolizumab. Cancer Med 7: 4870-4879, 2018. PMID: 30133176. DOI: $10.1002 /$ cam 4.1726

14 Sapkaroski D, Osborne C and Knight KA: A review of stereotactic body radiotherapy - is volumetric modulated arc therapy the answer? J Med Radiat Sci 62: 142-151, 2015. PMID: 26229679. DOI: $10.1002 /$ jmrs.108

15 Khan M, Lin J, Liao G, Li R, Wang B, Xie G, Zheng J and Yuan Y: Comparison of WBRT alone, SRS alone, and their combination in the treatment of one or more brain metastases: Review and meta-analysis. Tumour Biol 39: 1010428317702903, 2017. PMID: 28675121. DOI: 10.1177/1010428317702903

16 Brown PD, Gondi V, Pugh S, Tome WA, Wefel JS, Armstrong TS, Bovi JA, Robinson C, Konski A, Khuntia D, Grosshans D, Benzinger TLS, Bruner D, Gilbert MR, Roberge D, Kundapur V, Devisetty K, Shah S, Usuki K, Anderson BM, Stea B, Yoon H, Li J, Laack NN, Kruser TJ, Chmura SJ, Shi W, Deshmukh S, Mehta MP and Kachnic LA; for NRG Oncology: Hippocampal avoidance during whole-brain radiotherapy plus memantine for patients with brain metastases: Phase III trial NRG Oncology CC001. J Clin Oncol 38: JCO1902767, 2020. PMID: 32058845. DOI: $10.1200 /$ JCO.19.02767

Received March 25, 2020

Revised April 6, 2020

Accepted April 8, 2020 